\title{
Implementation of an occupational stress Control Model
}

\author{
Loredana Cristina Dascalu ${ }^{1}$, Gabriel Iacobescu ${ }^{1}$, Andrei Dimitrescu ${ }^{2}$, Augustin \\ Semenescu $^{3}$, and Valentin Petrescu ${ }^{4}$ \\ ${ }^{1}$ Welding and Material Technology Department, Politehnica University of Bucharest, Romania \\ ${ }^{2}$ Theory of Mechanisms and Robots Department, Politehnica University of Bucharest, Romania \\ ${ }^{3}$ Economics Engineering Department, Politehnica University of Bucharest, Romania \\ ${ }^{4}$ University "Lucian Blaga" Sibiu, Romania
}

\begin{abstract}
Occupational stress is an enemy of society, a problem that requires a deep research to control stress more effectively. The case study presented in this article consists of a model control regarding occupational stress. The experimental part of this study involved interviews with 15 employees, 9 females and 6 males aged between 25-55 years. Participants described stressful situations at work. Time allocated for each subject was 45 minutes per interviews. The model was implemented based on the job content stressors, effects of stress (physiological, psychological, behavioural) and interviews results. Future directions in stress research is to identify the way to have control in the workplace because, in my opinion, that it is the key factor for good results and health.
\end{abstract}

\section{Introduction}

The objective of the present article is to implement an occupational stress control model based on General Health Questionnaire, after ANOVA statistic. First, we test the reliability and validity of the GHQ. In simple ANOVA, total dispersion originates in two sources: intra-group (inside the group) and inter-group (between groups). Intergroup dispersion reflects deviations due to the different steps of the independent variable. The GHQ-12 was introduced by Goldberg [1] for reliability and has been translated into 38 foreign languages. The method used gives scores ranging from 0 to 12 [2].

This paper aims to present the study of measuring stress with General Health Questionnaire (GHQ-12) which it is the most used in research. The tool has been applied to the business environment in Peru and aim at identifying the stress effects.

\section{Literature review}

This questionnaire was expanded in 1970 and was originally with 60 -items test, but in the present is available with 12-items. The above tool it is used to evaluate well-being in a person. To determinate the scores it is used a bimodel scale (0-0-1-1) and Likert-type scale $(0-1-2-3)$ in four points [3-6]. We can obtain results regarding the risk of depression, anxiety, somatic symptoms and social withdrawal [ 7-12]. 
The form is simple to administer and to complete and it is used in many studies of occupational research [13-15].

The founding researcher in field of stress, Hans Selye defines the stress as a perception over a situation negative or positive from our lives. [16].

The ANOVA Analysis of Variance was introduced by the statistician Irving Fisher, and it has been used in order to test the significant difference between several averages. In the case of the comparison between two averages, the results are the same as the test for the difference between averages [17]. In this paper, I have used the ANOVA simple model.

The basic principle: the total variation comprises the sum of the variation between the groups, and the variation inside the groups. The dispersion analysis aims that, for every level of the causal factor(s), there be an analysis of both the distinct associated population, and the possible differences that may appear between populations.

Mathematical procedure involved in the simple ANOVA consists of the dispersion analysis of the dependent variable. In this type of analysis, the total dispersion has two components: the dispersion inside of every formed group and the dispersion between the averages of the groups and the total average (without taking into account the formed groups).

In simple ANOVA, the overall dispersion stems from two sources: inside the group (intragroup) and between the groups (intergroup). Both sources reflect the dispersion due to the randomized selection of the subjects. Moreover, the intergroup dispersion reflects the deviations caused by the different steps of the independent variable.

Dispersion due to random sampling is also known as error dispersion, while the dispersion due to the independent variable is also known as true dispersion. The theoretical parts of ANOVA and the model applied to the statistic interpretation have been adapted [18].

The independent $t$ test is a special type of simple ANOVA in which only two groups are involved. The simple ANOVA allows the evaluation of the null hypothesis between two or more series of data, on the condition that these be steps of the same independent variable [19].

\section{Methodology}

The current case study consists of a questionnaire in order to identify stress effects in the business environment:

- The General Questionnaire about the working environment and health status, to identify the effects of stress [20].

- General Questionnaire Scoring: Likert scale from 0 to 3. We have 12 questions, between 0 and 3 points each. Score between 0 and 36 points. The score varies depending on the studied population. The average score is 11-12.

- Score over 15 highlights stress.

- Score over 20 points out severe problems and psychological stress.

Procedure: the examination was completed in one session and we selected the persons. The group was made up of 15 subjects (9 women and 6 men), aged between 25 and 55 years, employees from the consultancy company of Peru. The research took place in February 2015.

Instruments: the 12-Item General Health Questionnaire (presented in table 1) for which we can interpret that the high scores indicate worse health [21]. Each item is rated as: less than usual, no more than usual, rather more than usual, or much more than usual [22]. 
Table 1. Items of form

\begin{tabular}{|c|l|}
\hline Nr. of questions & \multicolumn{1}{c|}{ GHQ-items } \\
\hline 1 & Able to concentrate \\
\hline 2 & Loss of sleep over worry \\
\hline 3 & Playing a useful part \\
\hline 4 & Capable of making decisions \\
\hline 5 & Felt constantly under strain \\
\hline 6 & Couldn't overcome difficulties \\
\hline 7 & Expert to enjoy day-to-day activities \\
\hline 8 & Apt to face problems \\
\hline 9 & Feeling unhappy and depressed \\
\hline 10 & Losing confidence \\
\hline 11 & Thinking of self as worthless \\
\hline 12 & Perception reasonably happy \\
\hline
\end{tabular}

The statistical and mathematical reading and processing of the data obtained through the applied research tools were achieved by using the following techniques:

- The drawing up of the tables and the logging of the data resulted from the GHQ questionnaire applied to the employees;

- The calculation of statistical indicators (theoretical average, standard deviation, dispersion/variance) by means of the ANOVA method;

- The statistical interpretation of the questionnaire.

The Anova statistic was used for data analyses which are described in the follow section.

\section{Experimental results}

Table 2 below sources the General Questionnaire surveys that were used in the business environment in Peru.

Table 2. Results of the form

\begin{tabular}{|c|c|c|}
\hline Respondent/Group & \multicolumn{2}{|c|}{ General Questionnaire } \\
\hline$/$ & $\mathbf{X}_{\mathbf{i}}$ & $\mathbf{X}^{\mathbf{2}}$ \\
\hline 1 & 7 & 49 \\
\hline 2 & 9 & 81 \\
\hline 3 & 3 & 9 \\
\hline 4 & 9 & 81 \\
\hline 5 & 13 & 169 \\
\hline 6 & 19 & 361 \\
\hline 7 & 11 & 121 \\
\hline 8 & 8 & 64 \\
\hline 9 & 15 & 225 \\
\hline 10 & 12 & 144 \\
\hline 11 & 9 & 81 \\
\hline 12 & 17 & 289 \\
\hline 13 & 13 & 169 \\
\hline 14 & 21 & 441 \\
\hline 15 & 14 & 196 \\
\hline TOTAL & $\mathbf{1 8 0}$ & $\mathbf{2 4 8 0}$ \\
\hline
\end{tabular}

The questionnaire (GHQ) that were used in this subsection represent the basis of the analysed data to which statistic calculations were applied using formulas (1) through (4). 


$$
\text { Average }=\frac{\sum_{i=1}^{15}{\text { Interview } \text { results }_{i}}_{15}}{15}=\frac{180}{15}=12
$$

Percentage of respondents without significant stress $/$ related issues $=\frac{12}{15}=80 \%$

Percentage of respondents with some stress/related issues $=\frac{2}{15}=13,33 \%$

Percentage of respondents with severe stress $/$ related issues $=\frac{1}{15}=6,66 \%$

Medium score: 12

The descriptive findings are presented in table 3, below:

Table 3. The characteristics of respondents

\begin{tabular}{|c|c|c|c|c|c|}
\hline Items & Age & Gender & $\begin{array}{c}\text { Educational } \\
\text { level }\end{array}$ & $\begin{array}{c}\text { Marital } \\
\text { status }\end{array}$ & Employment \\
\hline $25-35$ & 3 & & & & \\
\hline $35-45$ & 8 & & & & \\
\hline $45-55$ & 4 & & & & \\
\hline Female & & 9 & & & \\
\hline Male & & 6 & & & \\
\hline Primary/Secondary & & & 4 & & \\
\hline College/University & & & 11 & & \\
\hline Single & & & & 5 & \\
\hline Married & & & & 10 & \\
\hline Employed & & & & & 15 \\
\hline
\end{tabular}

The results of the statistic indicators for the GHQ can be found in the below table 4 :

Table 4. Statistic indicators

\begin{tabular}{|l|l|}
\hline Indicators & GHQ \\
\hline Average (m) & 12 \\
\hline Standard deviation (s) & 4,62 \\
\hline Variance (s $\mathbf{s}^{\mathbf{}}$ ) & 38,5 \\
\hline
\end{tabular}

The analysis for the General Health Questionnaire regarding the average are representing in the figure 1, below:

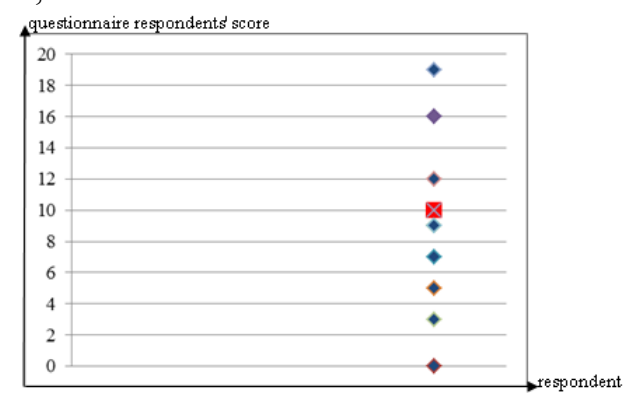

Fig. 1. Representation of the GHQ (Peru) average

The statistic processing of the questionnaires in this study case was done by means of the ANOVA method. The processing of the Cohen Questionnaire and the Holmes and Rahe Questionnaires was presented for illustration.

General questionnaire (GHQ) interpretation as follows, using formulas (5) through (24): 


$$
\begin{gathered}
\text { Average: } \mathrm{m}_{2}=\sum \frac{x_{i}^{2}}{n}=\frac{180}{15}=12 \\
\text { Standard deviation: } \tau=\sqrt{D}=4,62 \\
\text { Variability coefficient: } \mathrm{v}=\frac{\tau}{\mathrm{M}} \times 100=\frac{4,62}{12}=38,5 \%
\end{gathered}
$$

If $\mathrm{v}<35 \%$, means that the population is homogeneous.

Observation matrix it is represented in the table 5:

Table 5. Anova groups

\begin{tabular}{|c|c|c|c|c|c|c|c|c|}
\hline Nr Groups/Obs. & $\mathbf{1}$ & $\mathbf{2}$ & $\mathbf{3}$ & $\mathbf{4}$ & $\mathbf{5}$ & $\mathbf{6}$ & $\mathbf{7}$ & $\mathbf{8}$ \\
\hline I & 7 & 9 & 3 & 9 & 13 & 19 & 11 & 8 \\
\hline II & 15 & 12 & 9 & 17 & 13 & 21 & 14 & - \\
\hline
\end{tabular}

$$
\begin{gathered}
\mathrm{n}_{1}=8 ; \Rightarrow \mathrm{x}_{1}=\frac{79}{8}=9,87 \\
\mathrm{n}_{2}=7 ; \Rightarrow \mathrm{x}_{2}=\frac{101}{7}=14,42 \\
\mathrm{n}=\mathrm{n}_{1}+\mathrm{n}_{2}=15
\end{gathered}
$$

Average total selection: $\mathrm{M}=12$

The total sum of squares (SST) - the distance between all quotations that occur in the sample around the general average:

$$
\begin{gathered}
\mathrm{SST}=\sum_{i=1}^{15}(X i-M)^{2} \\
\mathrm{D}=\frac{1}{15} \sum_{i=1}^{15}(X i-M)^{2} \text { or } \frac{1}{15} \sum_{1}^{15} X i^{2}-\left(\frac{1}{15} \sum X i\right)^{2} \\
\Rightarrow 15 D=\sum_{1}^{15}(X i-M)^{2} \\
\mathrm{SST}=15 \times \mathrm{D}=15 \times 21,33=319,95 \\
\mathrm{SST}=\mathrm{SSB}+\mathrm{SSW} \text { parity, where: }
\end{gathered}
$$

SSB is the sum of squares between the groups, a measurement of variation between groups, which is calculated by adding up the squares of the distances from the average of each group to the general average. 
SSW is the sum of squares inside the groups, a measurement inside all groups, calculated by adding up the squares of the distances from each observation to the average of the group it belongs to.

$\mathrm{n}-$ Number of groups $=2 ; \overline{X i}=$ average group $\mathrm{i} ; \mathrm{K}=$ degree of freedom number $=2$ (number of groups)

$$
\begin{gathered}
\mathrm{SSW}=\sum_{i=1}^{2} \sum_{j=1}^{n i}(X i j-\overline{X i})^{2} \\
\mathrm{SSB}=\sum_{i=1}^{2} n i(\overline{X i}-M)^{2} \\
\mathrm{SSB}=8(9,87-12)^{2}+7(14,42-12)^{2}=77,19 \\
\mathrm{SSW}=\mathrm{SST}-\mathrm{SSB}=319,95-77,19=242,76
\end{gathered}
$$

The two estimates of the variance in quotations over the action can be rewritten in the following manner:

MSB (Average of Squares Between the Groups) - the variance between the groups' averages, where:

$$
\mathrm{MSB}=\frac{S S B}{k-1}=\frac{77,19}{2-1}=77,19
$$

MSW (Average of Squares Within the Groups) - the variance inside the groups, where:

$$
\begin{aligned}
& \mathrm{MSW}=\frac{S S W}{n-k}=\frac{242,76}{15-2}=18,67 \\
& \mathrm{MST}=\frac{S S T}{n-1}=\frac{319,95}{14}=22,85
\end{aligned}
$$

F statistics ANOVA (Snedecor- Fisher). The second step to take in order to achieve the variance analysis is calculating the $\mathbf{F}$ test statistics, as a ratio between the two estimates of variance:

$$
\mathrm{F}=\frac{M S B}{M S W}
$$

The way in which the F:MSW ratio is interpreted is very important and makes a good estimator of the variance in the $\sigma^{2}$ sample, regardless of whether or not the null hypothesis is true. This happens because MSW is based only on the variations inside each group, which, when brought together, offer a fairly good image (a fairly good estimate) for $\sigma^{2}$.

The part which is processed in the test is, however, MSB; if the null hypothesis is true (all averages are equal to one another), then MSB will also make a good estimator for $\sigma^{2}$. In 
this situation, MSB would have a value close to that of MSW, and the F value would be close to 1 .

The closer the $\mathrm{F}$ value is to 1 , the more increases the probability of an error due to the rejection of the null hypothesis. In the other situation, in which the null hypothesis was not true (i.e. if one of the averages differs substantially), the $F$ value would increase considerably; at the same time, the probability of error due to the rejection of the null hypothesis would decrease accordingly. This is due to the fact that the differences between groups tend to increase the MSB.

The F statistics show u show much variation is caused by the differences between the groups, relative to the variation generated by the randomized selection of the sample.

In other words, the total amount of variation equals the amount of variation explained through the differences between the groups plus the amount of variation that remains unexplained (random errors around the average); in short, the total variation equals the explained variation plus the unexplained variation.

The higher the explained variation would be, the lower the unexplained variation, hence a spectacular increase in the $\mathrm{F}$ value; conversely, the lower the explained variation (meaning that the differences between the groups are very small), the higher the unexplained variation (due to random errors), and therefore, the F value would tend to zero (a special case is when the groups are perfectly similar, without absolutely any difference between them, and then the explained variation equals zero).

Various statistics analysis software items may differ very little in the way they present the results, but they all refer to the same thing; any table of results will generally contain the following, cf. Table.6:

Table 6. ANOVA results

\begin{tabular}{|l|c|c|c|}
\hline Results & $\begin{array}{l}\text { Sum of squares- } \\
\text { Deviation }\end{array}$ & $\begin{array}{l}\text { Degree of } \\
\text { freedom number }\end{array}$ & Dispersion \\
\hline Between the groups & 77,19 & 1 & 77,19 \\
\hline Inside the groups & 242,76 & 13 & 18,67 \\
\hline Total & 319,95 & 4 & 22,85 \\
\hline
\end{tabular}

The splits of (n-1) $S^{2}$ as sum of 2 independents terms (k-1) $S_{1}{ }^{2}$ and (n-k) $S 2^{2}$ is called dispersion analysis. The 2 variables are assigned $\lambda_{k-1}^{2}$ and $\lambda_{n-k}^{2}$ divided into degrees of freedom, we get the Fisher repartition:

$$
\begin{gathered}
\mathrm{F}=\frac{77,19}{18,67}=4,13(\text { calculated }) \\
\mathrm{F}_{\text {calculated }}=4,13<\mathrm{F}_{\text {standard }}=4,67=\mathrm{F}_{\text {tabel }}=\mathrm{F}_{0,05 ;(1,13)}
\end{gathered}
$$

$\Rightarrow$ the stress doesn't influence the research population.

The $\mathrm{F}$ distribution has two degrees of freedom (for the numerator and for the denominator) and it is less dispersed as the degrees of freedom increase. The $\mathrm{F}$ value is on 
the horizontal axis and the probability it is represented by the vertical axis [23]. Tabel 7 shows the shape of the distribution.

Table 6. Values of the F distribution

\begin{tabular}{|c|c|c|c|c|c|c|c|c|}
\hline 1 & 2 & 3 & 4 & 5 & 6 & 7 & 8 & $\begin{array}{c}9 \\
P=0,95\end{array}$ \\
\hline 161.4 & 199.5 & 215.7 & 224.6 & 230.2 & 234.0 & 236.8 & 238.0 & 240.5 \\
\hline 18.51 & 19.00 & 19.16 & 19.25 & 19.30 & 19.33 & 19.35 & 19.37 & 19.38 \\
\hline 10.13 & 9.55 & 9.28 & 9.12 & 9.01 & 8.94 & 8.89 & 8.85 & 8.81 \\
\hline 7.71 & 6.94 & 6.59 & 6.39 & 6.26 & 6.16 & 6.09 & 6.04 & 6.00 \\
\hline 6.61 & 5.79 & 5.41 & 5.19 & 5.05 & 4.95 & 4.88 & 4.82 & 4.77 \\
\hline 5.99 & 5.14 & 4.76 & 4.53 & 4.39 & 4.28 & 4.21 & 4.15 & 4.10 \\
\hline 5.59 & 4.74 & 4.35 & 4.12 & 3.97 & 3.87 & 3.79 & 3.73 & 3.68 \\
\hline 5.32 & 4.46 & 4.07 & 3.84 & 3.69 & 3.58 & 3.50 & 3.44 & 3.39 \\
\hline 5.12 & 4.26 & 3.86 & 3.63 & 3.48 & 3.37 & 3.29 & 3.23 & 3.18 \\
\hline 4.96 & 4.10 & 3.71 & 3.48 & 3.33 & 3.22 & 3.14 & 3.07 & 3.02 \\
\hline 4.84 & 3.98 & 3.59 & 3.36 & 3.20 & 3.09 & 3.01 & 2.95 & 2.90 \\
\hline 4.75 & 3.89 & 3.49 & 3.26 & 3.11 & 3.00 & 2.91 & 2.85 & 2.80 \\
\hline 4.67 & 3.81 & 3.41 & 3.18 & 3.03 & 2.92 & 2.83 & 2.77 & 2.71 \\
\hline 4.60 & 3.74 & 3.34 & 3.11 & 2.96 & 2.85 & 2.76 & 2.70 & 2.65 \\
\hline 4.54 & 3.68 & 3.29 & 3.06 & 2.90 & 2.79 & 2.71 & 2.64 & 2.59 \\
\hline
\end{tabular}

\subsection{Implementation of a Control Model}

Before to complete the GHQ, we asked each subject to describe a stressful situation at work during at 45 minutes interview.

Participants were 15 employees from a consultancy company in Peru and we applied the questionnaire (GHQ) to measuring the stress. The GHQ is a well-known instrument for measuring the stress at work [24 - 25].

As per ANOVA statistics, the results were satisfactory, with medium stress level and we propose a model to control and to maintain the stress at the same level, or to minimize the stress at minimum. Figure 2. Shows the implementation of occupational stress- control model.

\section{$\mathbb{G H Q} \longrightarrow$ thainning session about stress}

\section{management at work}

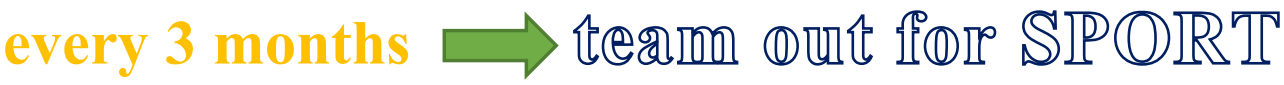 EXIERISES every (6 momiths im maturie $\longrightarrow$ STIRESS (body, mind,} emotions, behaviour) $\Rightarrow$ MUINIMIUMI/ MDEDIIUMI streess levell

Fig.2. Stress control - Model 


\section{Conclusions}

The results from present study showed that the quiz is a valid measure, but it should be noted that the employees were selected, and we cannot generalize for entire company.

Future research directions will be achieved by applying other tools and methods of calculation on a larger sample in order to detect with real approximation the stress effects from the business environment of Peru.

Considering all the above, the average score for the General Questionnaire on Work and Health was less then 15 points, which places the interviewed group outside of major stress risks.

The information obtained by experiment showed that the questionnaire can be used effectively to evaluate the health psychological among the employees.

The future directions regarding this article will be to continue the research based on control - Model proposed in figure 2.

\section{References}

1. Goldberg, DP.; et al. Manual of the General Health Questionnaire, NFER Publishing, Windsor, England (1978)

2. Goldberg, D. General Health Questionnaire (GHQ-12), NFER-Nelson, Windsor, UK (1992)

3. Goldberg, DP.; Blackwell, B. Psychiatric illness in general practice: A detailed study using a new method of case identification. British Medical Journal, 1, 439-443 (1970)

4. Jackson, C. The General Health Questionnaire. Occupational. Medicine 57, 79, doi:10.1093/occmed/kq1169 (2007)

5. Quek, KF.; Low, WY.; Razack, AH.; Loh, CS. Reliability and validity of the General Health Questionnaire (GHQ-12) among urological patients: A Malaysian study. Psychiatry and Clinical Neurosciences, 55, 509-513 (2001)

6. Maria, PSL,; Virginia, D. The 12-Item General Health Questionnaire (GHQ-12): Reliability, external validity and factor structure in the Spanish population. Psicothema, Vol. 20, 4, pp. 839843. ISSN $0214-9915$ (2008)

7. ***https://academic.oup.com/occmed/article/57/1/79/1557723 (accessed on 14.11.2018).

8. Mitchell, AM.; Crane, PA.; Kim, Y. Perceived stress in survivors of suicide: psychometric properties of the Perceived Stress Scale, Res Nurs Health, .31(6):576-85 (2008)

9. Rosenthal, T.; Alter, A. Occupational stress and hypertension, J Am Soc Hypertens, 6(1):2-22 (2012)

10. Richardson, S.; et al. Meta-analysis of perceived stress and its association with incident coronary heart disease, Am J Cardiol, 110(12):1711-6 (2012)

11. Kendler, KS.; et al. Life event dimensions of loss, humiliation, entrapment, and danger in the prediction of onsets of major depression and generalized anxiety, Arch Gen Psychiatry. 60(8):789-96 (2003)

12. Humphreys, J.; Lee, KA. Interpersonal violence is associated with depression and chronic physical health problems in midlife women, Issues Ment Health Nurs.30(4):206-13, (2009)

13. Feyer, AM.; Herbison, P.; Williamson, AM.; et al. The role of physical and psychological factors in occupational low back pain: a prospective cohort study, Occup Environ Med, vol. 57 pg. 116-120, (2000)

14. Jones, M.; Rona, RJ.; Hooper, R.; Wesseley.; S. The burden of psychological symptoms in UK Armed Forces, Occup Med (Lond), vol. 56, 322-328 (2006)

15. Stansfeld, SA.; Fuhrer, R.; Shipley, MJ.; Marmot, MG. Work characteristics predict psychiatric disorder:prospective results from the Whitehall II Study, Occup Environ Med, 1999, vol. 56 (pg. 302-307) Google Scholar, Crossref PubMed.

16. Selye, H. The Stress of Life, McGraw-Hill, New York.

17. ***, http://biblioteca.regielive.ro/cursuri/statistica/prezentare-anova-71437.html (accessed on 14.11.2018).

18. Târcolea, C. Suport de curs - Analiza de varianță, The Polytechnic University in Bucharest, 2014. 
19. ***, http://statisticasociala.tripod.com/anova.html (accessed on 04.11.2018).

20. ***, http://www.statisticssolucions.com/General-Health-Questionnaire (accessed on 15.10.2018).

21. Ali, M.; Amir, MH.; Mohammad, S.; Gholamreza, G.; Mehdi, E.; Abolfazl, F. The 12-item General Health Questionnaire (GHQ-12): translation and validation study of the Iranian version. Health Qual Life Outcomes. 1: 66. Published online 2003, doi: [10.1186/1477-7525-166] (2003)

22. Pevalin, DJ. Multiple applications of the GHQ-12 in a general population sample: an investigation of long-term retest effects. Soc Psychiatry Psychiatr Epidemio, 35:508-512. doi:10.1007/s001270050272 (2000)

23. ***, https://mysite.science.uottawa.ca/rkulik/mat3378/f.pdf (accessed on 10.11.2018).

24. Politi, PL.; Piccinelli, M.; Wilkinson, G. Reliability, validity and factor structure of the 12-item General Health Questionnaire among young males in Italy. Acta Psychiatr Scand. 1994 90:432437 (1994)

25. Doi, Y.; Minowa, M.; Factor structure of the 12-item General Health Questionnaire in the Japanese general adult population. Psychiatry Clin Neurosci, 57:379-383.doi:10.1046/j.14401819.2003.01135. x (2003) 